\title{
Characteristics of Keratoconus Patients in Jordan: Hospital-Based Population
}

This article was published in the following Dove Press journal:

Clinical Ophthalmology

\section{Noor Alqudah (1D \\ Hisham Jammal (1) \\ Yousef Khader $\mathbb{D}^{2}$ \\ Wedad Al-dolat (1D $)^{3}$ \\ Sarah Alshamarti ${ }^{1}$ \\ Zaki Shannak (D)}

'Department of Ophthalmology, Faculty of Medicine, Jordan University of Science and Technology, Irbid, Jordan;

${ }^{2}$ Department of Public Health, Community Medicine and Family Medicine, Faculty of Medicine, Jordan University of Science and Technology, Irbid, Jordan; ${ }^{3}$ Department of Ophthalmology, Faculty of Medicine, Yarmouk University, Irbid, Jordan
Correspondence: Noor Alqudah Department of Ophthalmology, Faculty of Medicine, Jordan University of Science and Technology, 3030 Ramtha Street, Irbid, 22II0, Jordan

Tel +00962798510010

Email nmalqudah5@just.edu.jo
Purpose: To study the demographic, clinical and topographic characteristics of keratoconus patients in Jordan.

Methods: A retrospective study which was conducted at King Abdullah University Hospital, Northern Jordan. The patients who visited our outpatient clinic from March 2015 to September 2020 and had a definite diagnosis of keratoconus were included in this study. Demographic and clinical data, including age, gender, family history, past ocular history, ophthalmic examination, and topographic parameters, were collected and analysed. Keratoconus severity was classified according to $\mathrm{K}$ mean readings.

Results: A total of 234 patients with keratoconus were evaluated in this study. The majority of patients $(73,31.2 \%)$ were between the ages of 20 and 24 . Allergic conjunctivitis was the most frequent past ocular history. Fifty-five patients $(23.5 \%)$ had a family history of keratoconus. Regarding severity, most of the eyes were mild (63.3\%), followed by moderate $(24.7 \%)$, and then severe $(11.9 \%)$. The severity of keratoconus was significantly associated with gender $(\mathrm{p}<0.001)$. No correlation was found between family history and severity.

Conclusion: Most of the Keratoconus patients were young, with a mean age of 25.9 years. The majority were mild in severity, with more females presented in the severe stage. The study reported high rate of family history $(23.5 \%)$ in comparison to similar studies. Therefore, screening of family members of Keratoconus patients is advisable.

Keywords: keratoconus, keratoconus characteristics, demographic profile, topographic parameters, Jordan

\section{Introduction}

Keratoconus $(\mathrm{KC})$ is a progressive corneal ectasia, characterized by thinning and protrusion of the cornea, leading to irregular astigmatism and myopia development, ${ }^{1,2}$ As a consequence, $\mathrm{KC}$ patients complain of blurred and distorted vision, halos, and/or regular changes in their prescriptions of spectacles. ${ }^{3,4}$ It progresses gradually, and may lead to severe vision impairment. Therefore, detection and efficient treatment of this disease is of paramount importance. ${ }^{5}$ The average prevalence in general population is 1.38 per 1000 population. ${ }^{6}$ Prevalence of $\mathrm{KC}$ varies widely across different populations depending on many factors like geographic location, genetic factors, diagnostic criteria used in different countries; it can range from 9 per 100,000 in Japan to 2300 per 100,000 in India. ${ }^{7}$

The etiology of the disease remains unknown. However, there is evidence of genetic inheritance and possible association with systemic disease. ${ }^{8}$ An association between $\mathrm{KC}$, atopy and excessive eye rubbing has been reported in some studies. $^{2,9,10}$ The occurrence of $\mathrm{KC}$ is also suggested to be greater in countries 
with dusty, hot and dry climates. ${ }^{11}$ It is believed that the environmental factors in genetically susceptible patients may cause the disease. ${ }^{11}$

Awareness of the relationship between demographic factors, clinical characteristics and topographic indices will help to plan a regular management protocol that not only important for diagnosis but also to organize an effective early detection and screening program. ${ }^{12-15}$ Several studies have examined these parameters in various ethnic groups. ${ }^{16-19}$

In Jordan, Abu Ameerh et al studied the epidemiological aspects of a group of $\mathrm{KC}$ patients who were referred for keratoplasty. ${ }^{20}$ The present study aimed to comprehensively investigate and study the demographic, clinical, and topographic characteristics of $\mathrm{KC}$ patients who attended a tertiary hospital in the north of Jordan.

\section{Materials and Methods Study Design and Setting}

This retrospective descriptive study was conducted at King Abdullah University Hospital (KAUH), Northern Jordan. The data of 263 patients who attended the ophthalmology clinic between March 2015 and September 2020 were retrieved from the electronic medical records database system of KAUH.

\section{Sample Size and Data Collection}

A total of 234 patients with $\mathrm{KC}$ were included in this study. Initially, a total of 263 patients were enrolled. However, 29 patients were excluded because of missing data. All available demographic and clinical data were collected, including age, gender, family history, systemic diseases, past ocular history. Data of ophthalmic examination were also collected, which included: visual acuity test using Snellen chart, manifest refraction, slit-lamp biomicroscopy findings and corneal topography parameters using Pentacam tomography (Oculus, Wetzlar, Germany). Diagnosis of KC was based on slit lamp exam (Central stromal thinning, Fleisher ring, Vogt's stria, and apical scar), refraction, and findings on corneal topography. Impact on daily activity and Occupation were assessed through interviews, either in person or over the phone. A questionnaire specific to our patients was constructed by reference to 25-item National Eye Institute Visual Functioning Questionnaire (NEI-VFQ 25) and used to assess the quality of vision-related daily activity. ${ }^{21}$ It included questions evaluating the following: Ocular Pain,
Near Activities, Distance Activities, Social Functioning, Dependency, Driving, and peripheral vision.

\section{Severity Assessment and Grouping}

Severity assessment was done by using $\mathrm{K}$ mean readings. The severity was classified into three groups, including mild: < 48 Diopter (D), moderate: $48-53$ D, and severe: > 53 D. Patients were grouped according to age into four bands: $<20$ years, $20-24$ years, $25-29$ years, and $\geq 30$ years.

\section{Ethics}

This study was approved ethically by the Institutional Review Board (IRB) of Jordan University of Science and Technology (Irbid, Jordan). Patients' consent to review their medical records was not required by the IRB because the research involved minimal risk, as the review of subjects' medical records was for limited information. The information was not sensitive in nature. A precaution was taken to limit the record review to specified data. Contacting subjects to obtain their consent could be considered an invasion of privacy and cause subjects undue anxiety. All study procedures were in accordance with the ethical standards of the institutional research committee and with the 1964 Helsinki declaration and its later amendments.

\section{Statistical Analysis}

SPSS 22.0 version was used to perform the statistical analysis. All variables were compared according to the age bands, gender and severity of the disease. Descriptive statistics were used to summarize the data. Variables were expressed as the mean \pm standard deviation (mean $\pm \mathrm{SD}$ ). Chi-square analysis was used to find the association between categorical variables. Statistical significance between the mean of three or more independent groups was assessed by using a one-way analysis of variance (ANOVA). Spearman correlation coefficient was used to assess the correlation between age and $\mathrm{K}$ mean. A P value of less than 0.05 was considered statistically significant.

\section{Results}

\section{Patients' Characteristics}

The socio-demographic and relevant characteristics of 234 patients with KC, 119 (50.9\%) males and 115 (49.1\%) females, are shown in Table 1. Their mean age was 25.9 $(\mathrm{SD}=6.9)$ years. Almost one-third of patients were 
Table I The Socio-Demographic and Relevant Characteristics of 234 Patients with KC

\begin{tabular}{|c|c|}
\hline & n (\%) \\
\hline \multicolumn{2}{|l|}{ Gender } \\
\hline Male & $119(50.9)$ \\
\hline Female & $115(49.1)$ \\
\hline \multicolumn{2}{|l|}{ Age in years } \\
\hline$<20$ & $40(17.1)$ \\
\hline $20-24$ & $73(31.2)$ \\
\hline $25-29$ & $60(25.6)$ \\
\hline$\geq 30$ & $61(26.1)$ \\
\hline \multicolumn{2}{|l|}{ Occupation } \\
\hline Employed office based & $33(14.1)$ \\
\hline Employed outside worker & $27(\mathrm{I} I .5)$ \\
\hline Unemployed $^{\mathrm{a}}$ & $109(46.6)$ \\
\hline Unknown & $65(27.7)$ \\
\hline Affecting his/her daily activity & $58(24.8)$ \\
\hline Presence of systemic disease & $19(8.1)$ \\
\hline Past ocular history (POH) & $60(25.6)$ \\
\hline Family history of $\mathrm{KC}$ & $55(23.5)$ \\
\hline Previous Cross linking (CXL) & $28(12.0)$ \\
\hline \multicolumn{2}{|c|}{ Consanguinity degree in presence of family history of $\mathrm{KC}$} \\
\hline Ist degree & $7(2.9)$ \\
\hline 2nd degree & $34(14.5)$ \\
\hline 3 rd degree & $6(2.6)$ \\
\hline 4th degree & $8(3.4)$ \\
\hline
\end{tabular}

Note: ${ }^{\text {a}}$ Students are included.

between the age of 20 to 24 years $(n=73,31.2 \%)$, and 30 $(12.8 \%)$ patients were in the pediatric age group $(\leq 18$ years old). The majority of patients were unemployed.

About one-fourth (24.8\%) of the patients reported that their vision-related daily activity was affected by their $\mathrm{KC}$ disease. About $8.1 \%$ of the patients had a systemic disease like Asthma, DM, hypothyroidism, or Down syndrome. About $23.5 \%$ of patients had a family history of KC.

Sixty $(25.6 \%)$ patients had a previous history of eye disease or surgery. Allergic conjunctivitis $(n=32$, $13.7 \%$ ) was the most frequent $\mathrm{POH}$ of $\mathrm{KC}$ patients, followed by Vernal keratoconjunctivitis $(n=14,6 \%)$. Seven $(2.9 \%)$ patients had Penetrating keratoplasty (PKP) in the contralateral eye, two $(0.9 \%)$ patients had strabismus surgery, three $(1.3 \%)$ patients underwent phacoemulsification surgery, and $2(0.9 \%)$ had intrastromal ring insertion.
Table 2 The Clinical Presentation of KC Patients

\begin{tabular}{|l|c|c|}
\hline Clinical Presentation & $\mathbf{n}$ & $\%$ \\
\hline Decreased vision & 166 & 70.9 \\
Eye deviation & $\mathrm{I}$ & 0.4 \\
Frequent change of glasses & 21 & 9.0 \\
Headache & 5 & 2.1 \\
Incidental & $\mathrm{II}$ & 4.7 \\
Itching & 2 & 0.9 \\
Multiple & 6 & 2.6 \\
Screening family history of KC & 3 & 1.3 \\
Seeking refractive surgery & 17 & 7.3 \\
Uncomfortable with glasses & $\mathrm{I}$ & 0.4 \\
White lesion on the cornea & $\mathrm{I}$ & 0.4 \\
Total & 234 & 100.0 \\
\hline
\end{tabular}

\section{Clinical Presentation of KC}

The clinical presentation of $\mathrm{KC}$ patients is shown in Table 2. Decreased vision $(70.9 \%)$ was the most common symptom associated with $\mathrm{KC}$ patients followed by frequent changes of glasses (9\%) and seeking for refractive surgery $(7.3 \%)$.

\section{Keratoconus Severity}

The number of eyes, according to KC severity, is shown in Figure 1. Seven eyes of 7 patients were excluded because they had Penetrating keratoplasty in the other eye due to the advanced stage of $\mathrm{KC}$. The number of eyes in the mild stage of $\mathrm{KC}$ was 292 eyes $(63.3 \%)$, followed by moderate $(114,24.7 \%)$ and severe stage $(55,11.9 \%)$. Among men and women, $73.5 \%$ and $25.8 \%$ of eyes had mild $\mathrm{KC}$, respectively.

Spearman correlation coefficient showed no significant correlation between age and $\mathrm{K}$ mean $(\mathrm{r}=-.001$; $\mathrm{p}$-value $=$ $0.983)$.However, women were significantly more likely than men to have severe $\mathrm{KC}$ (17.25 vs.7.2\%, p-value < $0.001)$. The distribution of the severity in individual eyes did not vary significantly according to family history of $\mathrm{KC}(\mathrm{p}=0.264)$.

\section{Clinical and Topographic Parameters}

The mean of quantitative parameters, including BCVA, sphere, cylinder, $\mathrm{K}$ mean, $\mathrm{K}$ max, and cornea thinnest location according to age and gender, are shown in Table 3, Table 4, respectively. There was a significant association between gender and the following parameters: BCVA, sphere, K max, and $\mathrm{k}$ mean. However, the results showed that only sphere was significantly associated with age. 


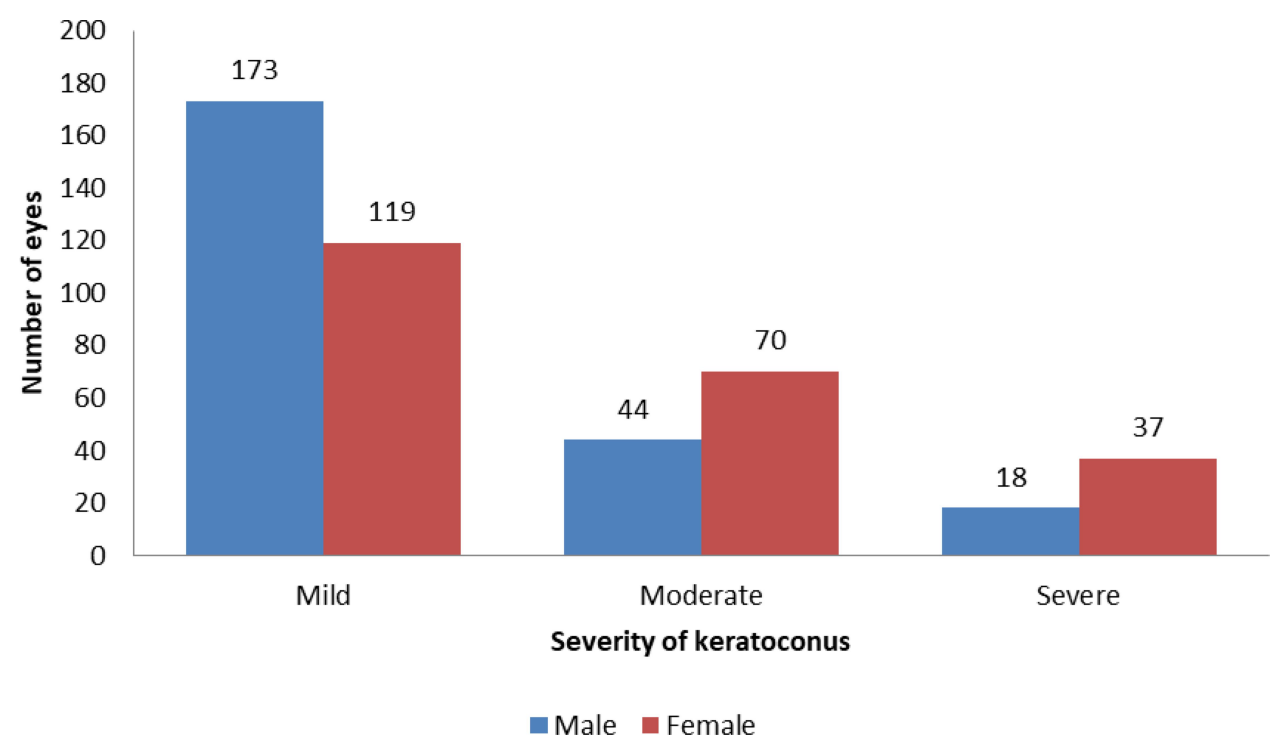

Figure I Number of eyes according to KC severity.

\section{Discussion}

Keratoconus $(\mathrm{KC})$ is a bilateral corneal, non-inflammatory condition characterized by gradual thinning and apical protrusion. ${ }^{22}$ It may result in a significant decrease in vision, which can contribute to the need for corneal transplantation at a young age. ${ }^{23}$ In different countries, KC prevalence varies, suggesting the possible role of genetics in its etiology. ${ }^{8,11}$ Several studies evaluated the demographic, clinical characteristics of patients with $\mathrm{KC}$ in different countries. ${ }^{24-27}$ In the present study, we assessed the characteristics of $234 \mathrm{KC}$ patients from a tertiary hospital in the northern region of Jordan.

Table 3 Clinical and Topographic Parameters According to Gender

\begin{tabular}{|l|r|r|r|r|r|r|r|}
\hline & \multicolumn{2}{|c|}{ Female } & \multicolumn{2}{c|}{ Male } & \multicolumn{2}{c|}{ Total } \\
\cline { 2 - 8 } & Mean & SD & Mean & SD & Mean & SD & P-value \\
\hline BCVA $^{\mathrm{a}}$ & 0.6 & 0.3 & 0.710 & 0.2797 & 0.673 & 0.2825 & 0.004 \\
Sphere & -1.7 & 2.5 & -0.8 & 2.3 & -1.2 & 2.5 & 0.000 \\
Cylinder & -2.9 & 1.7 & -2.8 & 1.6 & -2.8 & 1.6 & 0.499 \\
Cornea thinnest location & 455.5 & 55.5 & 461.9 & 50.0 & 458.8 & 52.8 & 0.192 \\
K mean $^{b}$ & 48.9 & 5.8 & 46.5 & 4.2 & 47.7 & 5.2 & 0.000 \\
K max $^{c}$ & 55.6 & 9.5 & 53.2 & 7.7 & 54.4 & 8.7 & 0.003 \\
\hline
\end{tabular}

Notes: ${ }^{a}$ Best-corrected visual acuity; ${ }^{b}$ keratometry mean; ${ }^{c}$ keratometry maximum.

Table 4 Clinical and Topographic Parameters According to Age

\begin{tabular}{|c|c|c|c|c|c|c|c|c|c|c|c|}
\hline & \multicolumn{2}{|c|}{$<20$} & \multicolumn{2}{|c|}{$20-24$} & \multicolumn{2}{|c|}{$25-29$} & \multicolumn{2}{|c|}{$\geq \mathbf{3 0}$} & \multicolumn{2}{|c|}{ Total } & \multirow[b]{2}{*}{ P-value } \\
\hline & Mean & SD & Mean & SD & Mean & SD & Mean & SD & Mean & SD & \\
\hline $\mathrm{BCVA}^{\mathrm{a}}$ & 0.7 & 0.3 & 0.7 & 0.3 & 0.7 & 0.3 & 0.6 & 0.3 & 0.7 & 0.3 & 0.249 \\
\hline Sphere & -0.7 & 2.0 & -0.7 & 1.6 & -1.6 & 2.4 & -1.8 & 3.3 & -1.2 & 2.5 & 0.000 \\
\hline Cylinder & -2.6 & 1.5 & -2.7 & 1.7 & -3.0 & 1.7 & -3.0 & 1.6 & -2.8 & 1.6 & 0.223 \\
\hline Cornea thinnest location & 460.0 & 48.7 & 460.9 & 50.7 & 454.9 & 63.1 & 459.3 & 46.8 & 458.8 & 52.8 & 0.828 \\
\hline $\mathrm{K}$ mean $^{\mathrm{b}}$ & 47.5 & 5.0 & 47.6 & 5.2 & 47.6 & 4.6 & 47.9 & 5.9 & 47.7 & 5.2 & 0.955 \\
\hline $\mathrm{K} \max ^{\mathrm{c}}$ & 53.6 & 7.6 & 54.9 & 8.8 & 54.3 & 8.2 & 54.5 & 9.7 & 54.4 & 8.7 & 0.757 \\
\hline
\end{tabular}

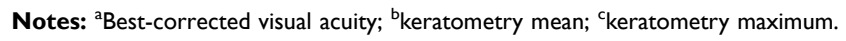


The male patients were slightly higher than the female patients in our study. Several studies have reported that the prevalence of KC was high in males. ${ }^{19,27,28}$ While other studies did not find differences between males and females, ${ }^{7,29,30}$ it is still unclear whether gender differences are significant or not.

In this study, the majority of $\mathrm{KC}$ patients were found in the age band of 20 to 24 years. The mean age was 25.9 years. Several studies conducted in various countries demonstrated that the mean age of $\mathrm{KC}$ patients was between 18 and 24 years in Asian countries, ${ }^{31-33}$ in the USA was 20 to 39 years, ${ }^{22,30}$ and 20 to 35 years in European countries. ${ }^{16,34}$

$\mathrm{KC}$ significantly influences the vision-related quality of life. ${ }^{35,36}$ Our findings showed that about one-fourth of the patients reported that their vision-related daily activity was affected by their KC disease. About $23.5 \%$ of the patients had a family history of KC. The family history rate was reported as $15 \%{ }^{37}$ and $13.5 \%{ }^{22}$ in $\mathrm{KC}$ patients in several large population studies. According to our results; the presence of family history does not affect severity. Szczotka-Flynn et al reported the same in their study. ${ }^{38}$

Allergic conjunctivitis was the most frequent childhood complaint of the patients in this study. It has been hypothesized that during forceful eye rubbing seen in patients with allergic conjunctivitis, protease activity increases and contributes to the development and progression of $\mathrm{KC}{ }^{39}$ Similarly, a recent study by Bencharki et $\mathrm{al}^{40}$ reported that allergic conjunctivitis plays a significant role in the progression and severity of KC. Many different theories have been suggested to explain the correlation between eye rubbing and development of $\mathrm{KC}$, like decrease in keratocytes density and changes in intraocular pressure (IOP) as a result of forced eye rubbing may lead to $\mathrm{KC}$ development and progression. ${ }^{41}$

According to the findings of our study, most of the patients had a mild level of KC (63.6\%) followed by moderate $(24.7 \%)$ and severe $(11.9 \%)$, in a recent study; Rana et al had similar results where mild cases were the most. ${ }^{42}$ Many Factors could explain the results. Using newer techniques and protocols for diagnosis and increasing awareness of $\mathrm{KC}$ disease may play a role in detecting the disease in the early stage.

In the current study, the severity of $\mathrm{KC}$ was significantly associated with gender $(\mathrm{P}<0.001)$, where more females presented with severe disease; several studies reported the effect of hormonal levels in the biomechanics of cornea and hence the progression of KC. ${ }^{43,44}$ Moreover, it is believed that an increase in estrogen level during pregnancy, menstrual cycle, or during hormonal replacement therapy (HRT) may influence the stiffness of the cornea and therefore play a role in the progression of $\mathrm{KC}^{44,45}$

On the contrary, our findings did not show a significant association between $\mathrm{KC}$ severity and age, which agrees with Rafati et al. ${ }^{25}$ Unfortunately, there is no worldwide consensus on the classification of $\mathrm{KC}$ severity; similar studies used different methods of severity characterization; this may influence the results and hence the comparability between studies.

The study is limited by its retrospective nature; some data were missing or not documented. The study setting was also one of the drawbacks of this study; we studied $\mathrm{KC}$ patients who visited our hospital, reducing the results' generalizability and increasing the selection bias. In this regard, more population-based studies are therefore warranted.

\section{Conclusion}

In this study, the majority of the $\mathrm{KC}$ patients were between 20 and 24 years old. Most of the patients with $\mathrm{KC}$ had a mild level of severity. Allergic conjunctivitis was the most past ocular history. There was a significant association between gender and severity, whereas severity did not vary according to a family history of $\mathrm{KC}$. However, the rate of family history (23.5\%) was high in comparison to other countries. We advise to screen the family members of patients with $\mathrm{KC}$.

The results of this study can be used during KC screening in Jordan, so early detection and intervention can be provided, and thus, better vision-related quality of life would be maintained for $\mathrm{KC}$ patients.

\section{Disclosure}

The authors report no funding or conflicts of interest for this work.

\section{References}

1. Kanski JJ, Bowling B. Clinical Ophthalmology: A Systematic Approach. Elsevier Health Sciences; 2011.

2. Romero-Jimenez M, Santodomingo-Rubido J, Wolffsohn JS. Keratoconus: a review. Contact Lens Anterior Eye. 2010;33 (4):157-166. doi:10.1016/j.clae.2010.04.006

3. Lim N, Vogt U. Characteristics and functional outcomes of 130 patients with keratoconus attending a specialist contact lens clinic. Eye. 2002;16(1):54-59. doi:10.1038/sj.eye.6700061

4. Weed KH, MacEwen CJ, Giles T, Low J, McGhee CNJ. The Dundee University Scottish Keratoconus study: demographics, corneal signs, associated diseases, and eye rubbing. Eye. 2008;22(4):534-541. doi:10.1038/sj.eye.6702692

5. Kymes SM, Walline JJ, Zadnik K, Sterling J, Gordon MO; Group CLE of KS. Changes in the quality-of-life of people with keratoconus. $\mathrm{Am}$ J Ophthalmol. 2008;145(4):611-617. doi:10.1016/j.ajo.2007.11.017 
6. Hashemi H, Heydarian S, Hooshmand E, et al. The prevalence and risk factors for keratoconus: a systematic review and meta-analysis. Cornea. 2020;39(2):263-270. doi:10.1097/ICO.0000000000002150

7. Omer K. Epidemiology of keratoconus worldwide. Open Ophthalmol J. 2018;12(1):289. doi:10.2174/1874364101812010289

8. Bykhovskaya Y, Margines B, Rabinowitz YS. Genetics in keratoconus: where are we? Eye Vis. 2016;3(1):1-10. doi:10.1186/s40662016-0047-5

9. Khor W-B, Wei RH, Lim L, Chan CM, Tan DT. Keratoconus in Asians: demographics, clinical characteristics and visual function in a hospital-based population. Clin Exp Ophthalmol. 2011;39 (4):299-307. doi:10.1111/j.1442-9071.2010.02458.x

10. Naderan M, Shoar S, Rezagholizadeh F, Zolfaghari M, Naderan M. Characteristics and associations of keratoconus patients. Contact Lens Anterior Eye. 2015;38(3):199-205. doi:10.1016/j.clae.2015.01.008

11. Gordon-Shaag A, Millodot M, Shneor E, Liu Y. The genetic and environmental factors for keratoconus. Biomed Res Int. 2015;2015:1-19. doi:10.1155/2015/795738

12. Fink BA, Wagner H, Steger-May K, et al. Differences in keratoconus as a function of gender. Am J Ophthalmol. 2005;140(3):459-e1. doi:10.1016/j.ajo.2005.03.078

13. Mihaltz K, Kovacs I, Takacs G, Nagy ZZ. Evaluation of keratometric, pachymetric, and elevation parameters of keratoconic corneas with Pentacam. Cornea. 2009;28(9):976-980. doi:10.1097/ ICO.0b013e31819e34de

14. Hashemi H, Beiranvand A, Yekta A, Maleki A, Yazdani N, Khabazkhoob M. Pentacam top indices for diagnosing subclinical and definite keratoconus. J Curr Ophthalmol. 2016;28(1):21-26. doi:10.1016/j.joco.2016.01.009

15. Wygledowska-Promie Ska D, Zawojska I. Procedure for keratoconus detection according to the Rabinowitz-Rasheed method-personal experience. Klin Oczna. 2000;102(4):241-244.

16. Barrientos YF, Moreno SG, Soto ML. Estimated prevalence and clinical characteristics of keratoconus in the healthcare setting of the Hospital Costa del Sol, Spain. J Emmetropia J Cataract Refract Corneal Surg. 2014;5(1):15-21.

17. Rashid ZA, Millodot M, Evans KSE. Characteristics of keratoconic patients attending a specialist contact lens clinic in Kenya. Middle East Afr J Ophthalmol. 2016;23(4):283. doi:10.4103/09749233.194074

18. Gokhale NS. Epidemiology of keratoconus. Indian J Ophthalmol. 2013;61(8):382. doi:10.4103/0301-4738.116054

19. Mohd-Ali B, Abdu M, Yaw CY, Mohidin N. Clinical characteristics of keratoconus patients in Malaysia: a review from a cornea specialist centre. J Optom. 2012;5(1):38-42. doi:10.1016/j.optom.2012.01.002

20. Abu Ameerh MA, Al Refai RM, Al Bdour MD. Keratoconus patients at Jordan University Hospital: a descriptive study. Clin Ophthalmol. 2012;6:1895.

21. Visual function questionnaire $25 \mid$ National eye institute [WWW document]. n.d.. Available from: https://www.nei.nih.gov/learnabout-eye-health/resources-for-health-educators/outreach-materials /visual-function-questionnaire-25. Accessed February 2, 2021.

22. Zadnik K, Barr JT, Gordon MO, Edrington TB. Biomicroscopic signs and disease severity in keratoconus. Cornea. 1996;15(2):139-146. doi:10.1097/00003226-199603000-00006

23. Brierly SC, Izquierdo JL, Mannis MJ. Penetrating keratoplasty for keratoconus. Cornea. 2000;19(3):329-332. doi:10.1097/00003226200005000-00014

24. Assiri AA, Yousuf BI, Quantock AJ, Murphy PJ. Incidence and severity of keratoconus in Asir province, Saudi Arabia. $\mathrm{Br}$ J Ophthalmol. 2005;89(11):1403-1406. doi:10.1136/bjo.2005.074955

25. Rafati S, Hashemi H, Nabovati P, et al. Demographic profile, clinical, and topographic characteristics of keratoconus patients attending at a tertiary eye center. J Curr Ophthalmol. 2019;31(3):268-274. doi:10.1016/j.joco.2019.01.013
26. Farrag AA. Keratoconus in the Omani Population; 2015.

27. Millodot M, Shneor E, Albou S, Atlani E, Gordon-Shaag A. Prevalence and associated factors of keratoconus in Jerusalem: a cross-sectional study. Ophthalmic Epidemiol. 2011;18(2):91-97. doi: $10.3109 / 09286586.2011 .560747$

28. Gorskova EN, Sevost'ianov EN. Epidemiology of keratoconus in the Urals. Vestn Oftalmol. 1998;114(4):38-40.

29. Pearson AR, Soneji B, Sarvananthan N, Sandford-Smith JH. Does ethnic origin influence the incidence or severity of keratoconus? Eye. 2000;14(4):625-628. doi:10.1038/eye.2000.154

30. Kennedy RH, Bourne WM, Dyer JA. A 48-year clinical and epidemiologic study of keratoconus. Am J Ophthalmol. 1986;101 (3):267-273. doi:10.1016/0002-9394(86)90817-2

31. Li SW, Li ZX, Shi WY, Zeng QY, Jin XM. Clinical features of 233 cases of keratoconus. Zhonghua Yan Ke Za Zhi. 2005;41(7):610.

32. Tanabe U, Fujiki K, Ogawa A, Ueda S, Kanai A. Prevalence of keratoconus patients in Japan. Nihon Ganka Gakkai Zasshi. 1985;89(3):407.

33. Sharma R, Titiyal JS, Prakash G, Sharma N, Tandon R, Vajpayee RB. Clinical profile and risk factors for keratoplasty and development of hydrops in north Indian patients with keratoconus. Cornea. 2009;28 (4):367-370. doi:10.1097/ICO.0b013e31818cd077

34. Nielsen K, Hjortdal J, Ehlers N, Ehlers N. Incidence and prevalence of keratoconus in Denmark. Acta Ophthalmol Scand. 2007;85 (8):890-892. doi:10.1111/j.1600-0420.2007.00981.x

35. Aydin Kurna S, Altun A, Gencaga T, Akkaya S, Sengor T. Vision related quality of life in patients with keratoconus. $J$ Ophthalmol. 2014;2014:1-7.

36. Wagner H, Barr JT, Zadnik K; Group CLE of K (CLEK) S. Collaborative longitudinal evaluation of keratoconus (CLEK) study: methods and findings to date. Contact Lens Anterior Eye. 2007;30 (4):223-232. doi:10.1016/j.clae.2007.03.001

37. Ihalainen A. Clinical and epidemiological features of keratoconus genetic and external factors in the pathogenesis of the disease. Acta Ophthalmol Suppl. 1986;178:1-64.

38. Szczotka-Flynn L, Slaughter M, McMahon T, et al. Disease severity and family history in keratoconus. $\mathrm{Br} J$ Ophthalmol. 2008;92 (8):1108-1111. doi:10.1136/bjo.2007.130294

39. Sharma N, Vajpayee R, Maharana P, Rao K. Ocular allergy and keratoconus. Indian J Ophthalmol. 2013;61(8):407. doi:10.4103/ 0301-4738.116063

40. Bencharki B. Comparative and Prospective Study of Kerato-Allergic Conjunctivitis Associated with Keratoconus. 2019:2.

41. Najmi H, Mobarki Y, Mania K, et al. The correlation between keratoconus and eye rubbing: a review. Int J Ophthalmol. 2019;12 (11):1775-1781. doi:10.18240/ijo.2019.11.17

42. Rana RS, Bajracharya L, Gurung R. Clinical profile on keratoconus presenting at a tertiary eye care centre-Tilganga institute of ophthalmology. Nepal J Ophthalmol. 2019;11(2):138-144. doi:10.3126/nepjoph.v11i2.27818

43. McKay TB, Hjortdal J, Sejersen H, Asara JM, Wu J, Karamichos D. Endocrine and metabolic pathways linked to keratoconus: implications for the role of hormones in the stromal microenvironment. Sci Rep. 2016;6(1):25534. doi:10.1038/srep25534

44. Spoerl E, Zubaty V, Raiskup-Wolf F, Pillunat LE. Oestrogen-induced changes in biomechanics in the cornea as a possible reason for keratectasia. $\quad B r \quad J \quad$ Ophthalmol. 2007;91(11):1547-1550. doi:10.1136/bjo.2007.124388

45. Coco G, Kheirkhah A, Foulsham W, Dana R, Ciolino JB. Keratoconus progression associated with hormone replacement therapy. Am J Ophthalmol Case Rep. 2019;16:15. 


\section{Publish your work in this journal}

Clinical Ophthalmology is an international, peer-reviewed journal covering all subspecialties within ophthalmology. Key topics include: Optometry; Visual science; Pharmacology and drug therapy in eye diseases; Basic Sciences; Primary and Secondary eye care; Patient Safety and Quality of Care Improvements. This journal is indexed on PubMed

Submit your manuscript here: https://www.dovepress.com/clinical-ophthalmology-journal
Central and CAS, and is the official journal of The Society of Clinical Ophthalmology (SCO). The manuscript management system is completely online and includes a very quick and fair peer-review system, which is all easy to use. Visit http://www.dovepress.com/ testimonials.php to read real quotes from published authors. 